\title{
Situs Inversus Totalis with Left-Sided Appendicitis: A Case Report
}

\author{
Mohsen Kamel Arid \\ Radiology Department, Faculty of Medicine, Benha University, Benha, Egypt \\ Email: mkarid2002@yahoo.com
}

How to cite this paper: Arid, M.K. (2020) Situs Inversus Totalis with Left-Sided Appendicitis: A Case Report. Open Journal of Clinical Diagnostics, 10, 104-114. https://doi.org/10.4236/ojcd.2020.104009

Received: November 17, 2020

Accepted: December 27, 2020

Published: December 30, 2020

Copyright (C 2020 by author(s) and Scientific Research Publishing Inc. This work is licensed under the Creative Commons Attribution International License (CC BY 4.0).

http://creativecommons.org/licenses/by/4.0/

\begin{abstract}
Introduction: Left-sided acute appendicitis (LSAA) develops in association with two types of congenital anomalies: situs inversus totalis (SIT) and midgut malrotation (MM). A Left sided appendicitis is an ambiguous and difficult diagnosis to make. Aim: To present a proven case of left-sided acute appendicitis (LSAA) associated with situs inversus totalis (SIT). Case Report: A case of Left appendicitis was evaluated in a 28-year-old Asian male, who presented to our hospital in Feb. 2016, with lower abdominal pain more on left side and suspected diverticulitis or acute appendicitis with unusual appendix location. The patient doesn't recall any history of abdominal surgery or about situs inversus totalis, abdominal and pelvic ultrasound was done, left iliac fossa appendicitis was diagnosed, Erect chest X-ray including upper abdomen revealed dextrocardia and stomach air on right side (situs inversus totalis), the patient underwent diagnostic Laproscop and Endoscopic resection of the appendix, with no incidents, and then discharged without complications, follow visits went unremarkable. Conclusion: The diagnosis of left lower quadrant pain is based on well-established clinical symptoms, physical examination and physician's experience.
\end{abstract}

\section{Keywords}

Left Lower Quadrant Pain, Left-Sided Appendicitis (LSAA), Midgut

Malrotation (MM), Situs Inversus Totalis (SIT)

\section{Introduction}

Acute appendicitis is a common condition requiring emergency surgery. The diagnosis is based on clinical symptoms, basic radiologic findings and surgeon experience [1] [2]. Approximately one third of patients with acute appendicitis have pain localized outside of the right lower quadrant because of the various 
positions of the appendix vermiformis, i.e. retrocecal, pelvic, subcecal, preileal and postileal, while subhepatic, meso-celiac, mid-inguinal and left-sided are seen more rarely [1] [2].

Appendicitis causing pain in the left lower quadrant is extremely rare and can occur with congenital abnormalities that include true left-sided appendix or as an atypical presentation of right-sided, but long appendix, which projects into the left lower quadrant [2]. Left-sided acute appendicitis (LSAA) develops in association with two types of congenital anomalies: situs inversus totalis (SIT) and midgut malrotation (MM) [1]-[65]. I am presenting an unusual case of SIT with acute appendicitis presenting as left lower abdominal pain.

\section{Case Report}

A 28-year-old male presented to the emergency unit on Feb., 16, 2016 (private famous hospital in Abu Dhabi, UAE) with severe abdominal pain, which started the previous night. The patient stated that the pain has begun first in the epigastric area and later expanded through the left lower quadrant. Patient history revealed no previous illness or surgery. The patient recalled no information about having intestinal malrotation or situs inversus. On physical examination, rebound tenderness was observed in the lower quadrant more on left side. Laboratory tests, showed high CRP titer, and high leukocyte count, normal urinalysis, normal liver and kidney function tests, normal ECG. Based on the patient's clinical status, the ER doctor send him for abdominal ultrasonography for suspected diverticulitis or acute appendicitis.

Abdominal ultrasonography (USG) done first, We usually examine the upper abdominal organs first then the lower, the liver was located in left hypochondrium and spleen on right side suggesting Situs inversus which later confirmed by taken chest X-ray. The appendix was not visualized in right iliac fossa but a dilated non-compressible blind intestinal loop consistent with acute appendicitis was located in the left lower quadrant (Figure 1(a) \& Figure 1(b)). Chest X-ray was taken 4 hours later after admission, revealed dextrocardia (Figure 2) and the patient was immediately taken to surgical suite and laparoscopic appendectomy was performed, the surgeon confirmed the diagnosis, the operative details was videotaped and kept in hospital records. The patient was going well, and discharged on the third postoperative day with no complications. Follow-up visits for him was unremarkable and went smoothly. The patient was informed of his condition for future medical consultation or surgical intervention.

\section{Review of Literature about Left-Sided Appendicitis}

PubMed and Google Scholar databases was reviewed (all articles from 1893 to July 2010) and 64 reports concerning 95 cases of LSAA meeting the above-mentioned criteria were included in this review [1]-[64]. The patients were aged from 8 to 82 years (mean: $29.1 \pm 15.9$ years). Fifty-seven were male and 38 were female. Sixty-six patients had SIT, 23 had MM, 3 had cecal malrotation, in two the anomaly was previously unnoted and in one case, the end of the 


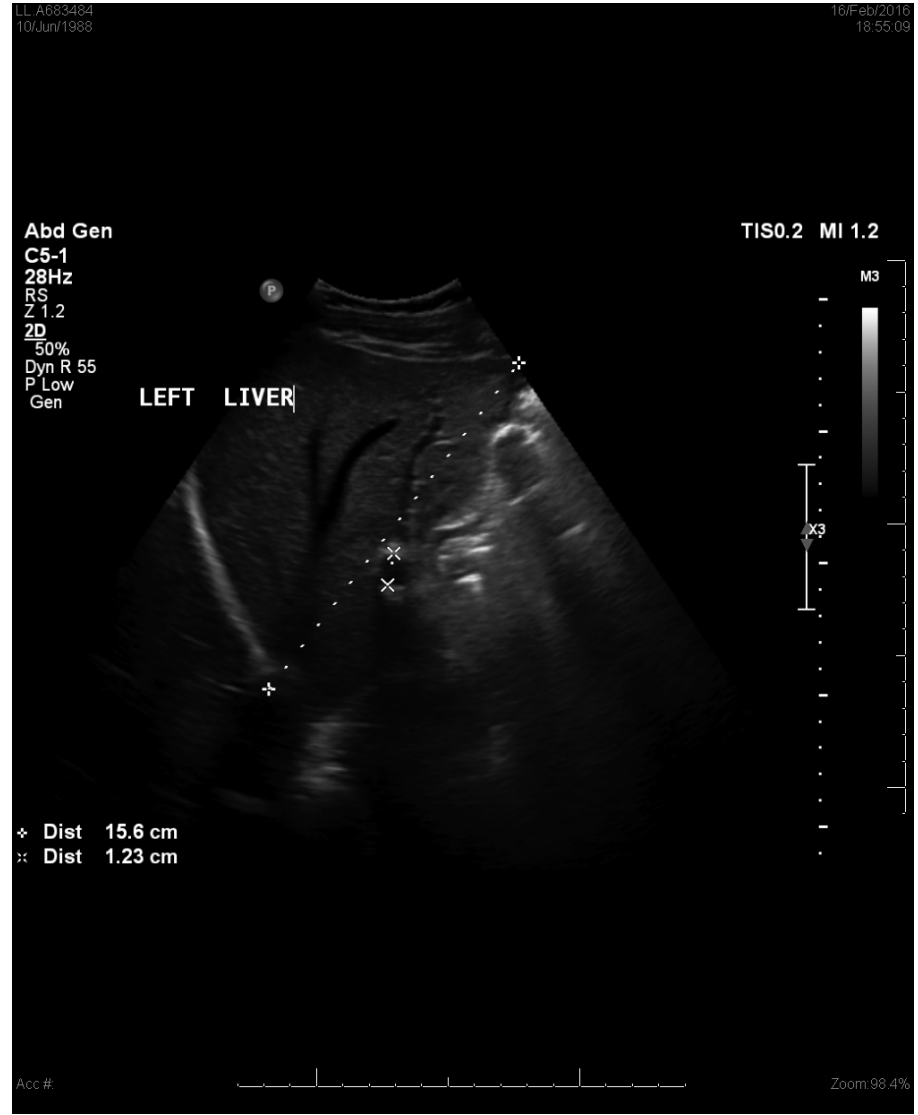

(a)

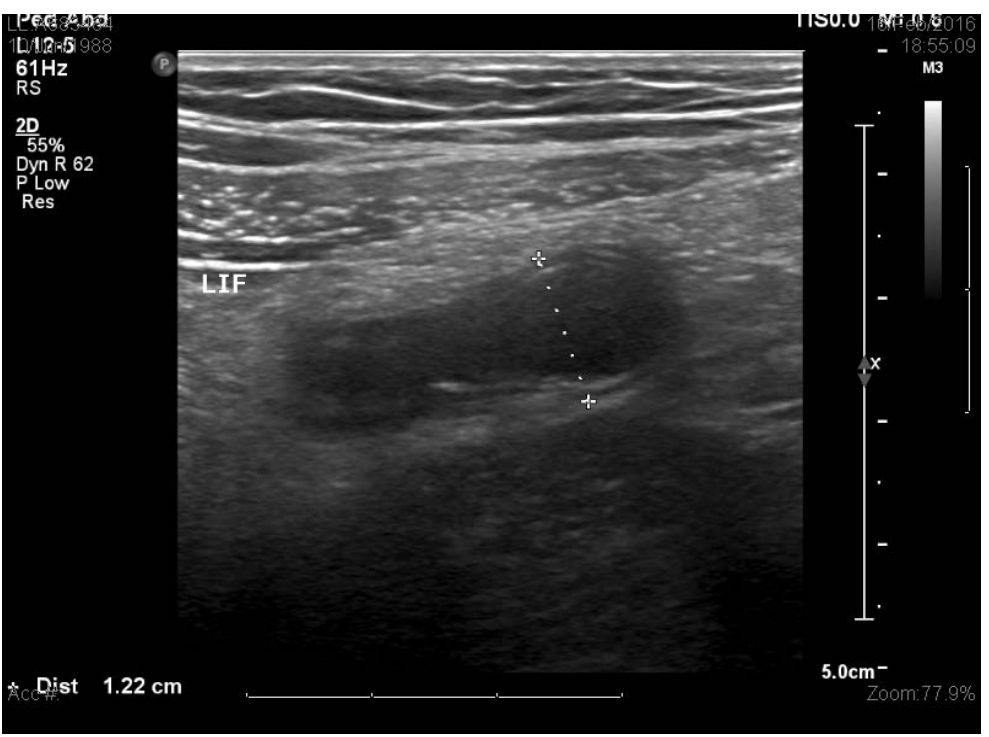

(b)

Figure 1. (a) and (b) Ultrasonography of abdomen and pelvis, showed situs inversus totalis including reversed position of liver and spleen. The right iliac fossa was examined, the appendix was not visualized but the left iliac fossa showed signs of acute appendicitis, in the form of distended fluid-filled appendix at $12.2 \mathrm{~mm}$ in diameter and seen non-compressible with thick wall, no periappendiceal fluid, and no appendicolith seen, the same patient name, the same ID and the same hospital were displayed on the 3 original images provided (all patient identity information will removed in final version). 


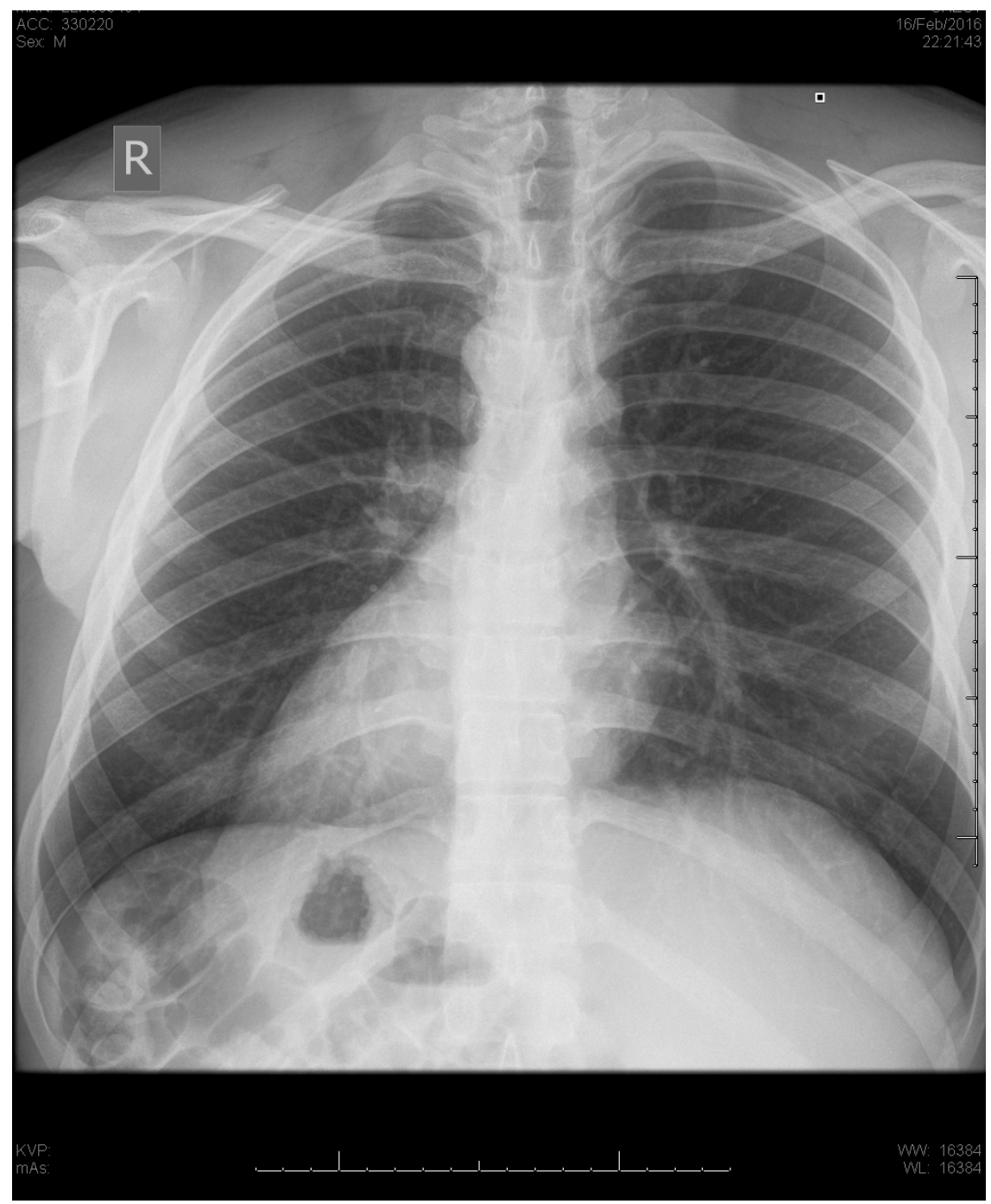

Figure 2. Chest X-ray was done 4 hours later for confirmation of dextrocardia.

appendix running along the anterior side of sacrum was found in the left side. According to localization of the symptoms, 59 patients presented with left and 14 with right lower quadrant pain, 7 with bilateral lower quadrant pain, 7 with left upper quadrant pain, 6 with peri-umbilical, and two presented with pelvic pain. With regard to the diagnosis, 49 patients were diagnosed with appendicitis during the pre-operative period, in 19 patients, the diagnosis was established intraoperatively and in 5 postoperatively; 14 patients were previously known to have SIT and/or MM. No information was available in eight patients. Of 95 patients included in this literature review, 13.6\% (13 cases) of patients underwent Laparoscopic appendectomy [66].

\section{Discussion}

It is important to differentiate LSAA associated with malrotation from that associated with situs inversus totalis, in which every organ, including duodenum, duodenojejunal junction, small and large bowel, cecum, and appendix, is located 
in a mirror position to situs solitus [1]. In addition to these features, a left-sided liver and right-sided spleen and stomach serve as clues to the correct diagnosis of situs inversus totalis. Chest X-ray is important to obtain at this point for ruling out situs inversus totalis which may be confused with intestinal malrotation. More than two-thirds of the left-sided appendicitis is due to situs inversus totalis rather than intestinal malrotation [66].

MM is the term used to describe a spectrum of congenital positional anomalies of the intestine caused by nonrotation or incomplete rotation of the primitive loop around the axis of the superior mesenteric artery (SMA) during fetal life. Although about $80 \%$ of cases are diagnosed in patients younger than 1 month, malrotation has also been reported in adults [8]. The incidence of MM cited in the literature varies from $0.03 \%$ to $0.5 \%$ in live births [1] [3] [9] [10]. The situs inversus may be complete (SIT), when both thoracic and abdominal organs are transposed, or partial, when only one of those cavities is affected [1]. The incidence of SIT reported in the literature varies from $0.001 \%$ to $0.01 \%$ in the general population [12] [13] [14], whereas the incidence of acute appendicitis associated with SIT is reported to be between $0.016 \%$ and $0.024 \%$ [5] [13] [14].

In the literature, LSAA occurs between the age of 8 and 63 years and is 1.5-fold more frequent in men than in women [3] [13].

The differential diagnosis of left lower quadrant abdominal pain includes: diverticulitis, renal colic, ruptured ovarian cyst, Meckel's diverticulitis, epididymitis, incarcerated or strangulated hernia, bowel obstruction, regional enteritis, psoas abscess, and right- and left-sided appendicitis (LSAA) [1] [4].

LSAA is a diagnostic dilemma, because the appendix is located in an abnormal position. The differential diagnosis of LSAA may not be promptly established in the emergency setting and is often delayed due to lack of uniformity in the clinical signs [11] [58]. It is assumed that even though the viscera are transposed, the nervous system may not show the corresponding transposition, which may result in confusing symptoms and signs. In about $18.4 \%-31 \%$ of patients with SIT and MM, the pain caused by LSAA has been reported in the right lower quadrant [1] [5] [11] [12] [13]. In this literature review, it was observed that $14.7 \%$ of patients had pain localized in the right lower quadrant, which indicates the importance of accurate preoperative diagnosis in order to avoid incorrect incision.

The diagnosis of acute appendicitis in patients with SIT or MM can be based on physical examination, electrocardiogram, chest X-ray, barium studies, USG, CT scan and diagnostic laparoscopy [1] [2].

Plain radiographs are usually not helpful for establishing the diagnosis of appendicitis. However, the detection of dextrocardia on chest X-ray and right-sided gastric bubble on abdominal plane $\mathrm{X}$-ray is of considerable value in establishing the diagnosis of SIT, as demonstrated in our case the chest X-ray was conclusive. Barium enema with gastrografin can reveal MM or SIT, when there are difficulties in making the diagnosis of acute left lower quadrant pain [11]. Over the last 
two decades, there has been an increasing use of imaging modalities, such as USG and CT, in the diagnosis of acute appendicitis, we didn't use enhanced CT scanning of the abdomen, because our case was straight-forward and because of insurance limitations for private hospital. USG is widely used in cases of appendicitis, however, it has significant limitations: it is operator-dependent, and examination of the lower quadrant can be compromised in patients with large body habitus or by overlying bowel gas. The value of CT in the diagnosis of acute appendicitis has been well-documented, with a reported accuracy of $90 \%$ 98\% [2] [13]. USG and CT may also be helpful in the detection of SIT and MM. Of the patients included in this literature review, CT has been used in the diagnosis of 28 patients and USG in 22 patients since 2000 [1] [6] [8] [17]-[24] [26] [27]. USG in our case was acurate in diagnsig situs inversus and in depacting non-complicated acute appendicitis because was not fat and bowel distension.

After establishing the diagnosis of SIT or MM, the surgical options are the same as for normal patients [1]. According to the reviewed literature, it was observed that many open and a few laparoscopic procedures have been performed [1] [6] [8] [15]. Laparoscopic appendectomy was first carried out in 1998 by Contini et al. [58] in a 34-year-old male patient with SIT. Since then, laparoscopic appendectomy has been performed in a total of 20 cases (12 with MM and 8 with SIT), of which two have undergone cholecystectomy at the same surgical session [3] [6] [7] [10] [12] [13] [15] [21] [24] [41] [58] [65]. Laparoscopy may be very useful both in establishing the differential diagnosis and in performing the definitive surgery [1].

As in patients with normally localized appendix, appendectomy specimens in LSAA should be sent for pathological evaluation. In the literature, only two of 95 patients (59 male, 76 female), who underwent appendectomy due to LSAA, were pathologically diagnosed with malignancy. Ascendent hemicolectomy was performed in both patients after pathological evaluation, which revealed mucinous adenocarcinoma and mucinous cystadenocarcinoma [19] [26]. In our case, the diagnosis was acute left sided appendicitis with no complications, no fluid collection, or abscess formation and successful endoscopic appendectomy was done, the caecum was located in left lower abdomen, the SIT was confirmed the surgery was videotaped and saved in hospital records, the pathological specimen showed signs of acute inflammation in the appendix. Ultrasonography before discharging the patient was unremarkable. The patient was doing well in his follow up visits.

\section{Conclusion}

LSAA should be considered in the differential diagnosis of young patients presenting with pain localized in the left lower quadrant. Chest X-ray, abdominal USG and CT provide very useful information. Endoscopic appendectomy in straight-forward cases and Diagnostic laparoscopy is the gold standard in cases with complicated differential diagnosis. 


\section{Patient Consent for Publication}

The patient consented for images or clinical information relating to his case to be reported in a medical publication.

\section{Conflicts of Interest}

The author declares no competing interests in relation to their work.

\section{References}

[1] Akbulut, S., Caliskan, A., Ekin, A. and Yagmur, Y. (2010) Left-Sided Acute Appendicitis with Situs Inversus Totalis: Review of 63 Published Cases and Report of Two Cases. Journal of Gastrointestinal Surgery, 14, 1422-1428. https://doi.org/10.1007/s11605-010-1210-2

[2] Hou, S.K., Chern, C.H., How, C.K., Kao, W.F., Chen, J.D., Wang, L.M. and Huang, C.I. (2005) Diagnosis of Appendicitis with Left Lower Quadrant Pain. Journal of the Chinese Medical Association, 68, 599-603. https://doi.org/10.1016/S1726-4901(09)70101-7

[3] Franklin Jr., M.E., Almeida, J.A., Pérez, E.R., Michaelson, R.L.P. and Majarrez, A. (2001) Cholecystectomy and Appendectomy by Laparoscopy in a Patient with Situs Inversus Totalis: A Case Report and Review of the Literature. Asociación Mexicana de Cirugía Endoscópica, 2, 150-153.

[4] Lee, M.R., Kim, J.H., Hwang, Y. and Kim, Y.K. (2006) A Left-Sided Periappendiceal Abscess in an Adult with Intestinal Malrotation. World Journal of Gastroenterology, 12, 5399-5400. http://dx.doi.org/10.3748/wjg.v12.i33.5399

[5] Van Steensel, C.J. and Wereldsma, J.C. (1985) Acute Appendicitis in Complete Situs Inversus. Netherlands Journal of Surgery, 37, 117-118.

[6] Bedoui, R., Ali Ouaer, M., Nouira, R. and Dziri, C. (2009) Acute Left-Sided Appendicitis. Tunisian Medical, 87, 873-874.

[7] Song, J.Y., Rana, N. and Rotman, C.A. (2004) Laparoscopic Appendectomy in a Female Patient with Situs Inversus: Case Report and Literature Review. Journal of the Society of Laparoendoscopic Surgeons, 8, 175-177.

[8] Nicholas, J.M. and Rozycki, G.S. (2001) Special Feature: Image of the Month. Diagnosis: Acute Left-Sided Appendicitis. Archives of Surgery, 136, 705-706.

[9] Israelit, S., Brook, O.R., Nira, B.R., Guralnik, L. and Hershko, D. (2009) Left-Sided Perforated Acute Appendicitis in an Adult with Midgut Malrotation: The Role of Computed Tomography. Emergency Radiology, 16, 217-218. https://doi.org/10.1007/s10140-008-0746-x

[10] Welte, F.J. and Grosso, M. (2007) Left-Sided Appendicitis in a Patient with Congenital Gastrointestinal Malrotation: A Case Report. Journal of Medical Case Reports, 1, Article No. 92. https://doi.org/10.1186/1752-1947-1-92

[11] Ahmed, J.U., Hossain, G.M.Z., Karim, M.M., Hossain, A.S.M.I., Ahmed, M. and Bhuya, M.S.A. (2007) Left Sided Acute Appendicitis with Situs Inversus in an Elderly-An Unusual Case. Journal of Chittagong Medical College Teachers Association, 18, 29-31. https://doi.org/10.3329/jcmcta.v18i1.3818

[12] Golash, V. (2006) Laparoscopic Management of Acute Appendicitis in Situs Inversus. Journal of Minimal Access Surgery, 2, 220-221.

[13] Perera, W.R. and Hennessy, O.F. (2010) An Unusual Case of Appendicitis. The American Journal of Surgery, 199, e79-e81. 
https://doi.org/10.1016/j.amjsurg.2009.08.047

[14] Huang, S.M., Yao, C.C., Tsai, T.P. and Hsu, G.W. (2008) Acute Appendicitis in Situs Inversus Totalis. Journal of the American College of Surgeons, 207, 954.

https://doi.org/10.1016/j.jamcollsurg.2008.03.030

[15] Schwartz, J.H. and Manco, L.G. (2008) Left-Sided Appendicitis. Journal of the American College of Surgeons, 206, 590. https://doi.org/10.1016/j.jamcollsurg.2007.05.019

[16] Seifmanesh, H., Jamshidi, K., Kordjamshidi, A., Delpisheh, A., Peyman, H. and Yasemi, M. (2010) Acute Left-Sided Appendicitis with Situs Inversus Totalis: A Case Report. American Journal of Emergency Medicine, 28, 1058.E5-1058.E7. https://doi.org/10.1016/j.ajem.2010.01.020

[17] Pillow, M.T. and Valle, C. (2010) Appendicitis in an Uncommon Location. The Western Journal of Emergency Medicine, 11, 115.

[18] Cissé, M., Touré, A.O., Konaté, I., Dieng, M., Ka, O., Touré, F.B., Dia, A. and Touré, C.T. (2010) Appendicular Peritonitis in Situs Inversus Totalis: A Case Report. Journal of Medical Case Reports, 4, Article No. 134. https://doi.org/10.1186/1752-1947-4-134

[19] Petrou, A., Papalambros, A., Katsoulas, N., Bramis, K., Evangelou, K. and Felekouras, E. (2010) Primary Appendiceal Mucinous Adenocarcinoma Alongside with Situs Inversus Totalis: A Unique Clinical Case. World Journal of Surgical Oncology, 8, Article No. 49. https://doi.org/10.1186/1477-7819-8-49

[20] Abboud, B. and Daher, R. (2009) An Exceptional Cause of Left Lower Quadrant Abdominal Pain. World Journal of Gastroenterology, 15, 3451. http://dx.doi.org/10.3748/wjg.15.3451

[21] Hassan, A.A., El Sabagh, A. and Helmy, A.H. (2008) Laparoscopic Management of Acute Appendicitis in Situs Inversus Totalis. The Egyptian Journal of Surgery, 27, 213-215.

[22] Pinto, A., Di Raimondo, D., Tuttolomondo, A., Fernandez, P., Caronia, A., Lagalla, R., Arnao, V., Law, R.L. and Licata, G. (2007) An Atypical Clinical Presentation of Acute Appendicitis in a Young Man with Midgut Malrotation. Radiography, 13, 164-168. https://doi.org/10.1016/j.radi.2005.10.010

[23] Lin, C.J., Tiu, C.M., Chou, Y.H., Chen, J.D., Liang, W.Y., Chang, C.Y. (2004) CT Presentation of Ruptured Appendicitis in an Adult with Incomplete Intestinal Malrotation. Emergency Radiology, 10, 210-212.

https://doi.org/10.1007/s10140-003-0316-1

[24] Tsumura, H., Ichikawa, T., Kagawa, T. and Nishihara, M. (2003) Successful Laparoscopic Ladd's Procedure and Appendectomy for Intestinal Malrotation with Appendicitis. Surgical Endoscopy and Other Interventional Techniques, 17, 657-658. https://doi.org/10.1007/s00464-002-4516-7

[25] Keith, J.C., Thoma, J.J., Bugay, S.J., Price, P.D. and Smear, J. (2003) Asymptomatic Midgut Rotational Anomalies in Adults: 2 Case Reports and Review of the Literature. Contemporary Surgery, 59, 322-325.

[26] Sato, H., Fujisaki, M., Takahashi, T., Maruta, M., Maeda, K. and Kuroda, M. (2001) Mucinous Cystadenocarcinoma in the Appendix in a Patient with Nonrotation: Report of a Case. Surgery Today, 31, 1012-1015. https://doi.org/10.1007/s005950170014

[27] Zissin, R., Kots, E., Shpindel, T. and Shapiro-Feinberg, M. (2000) Acute Appendicitis with Intestinal Non-Rotation Presenting with Partial Small Bowel Obstruction Diagnosed on CT. The British Journal of Radiology, 73, 557-559. 
https://doi.org/10.1259/bjr.73.869.10884757

[28] Carmichael, K. and Gayle, W. (1979) Situs Inversus and Appendicitis. Southern Medical Journal, 72, 1147-1149. https://doi.org/10.1097/00007611-197909000-00020

[29] Shapiro, N.M., Michels, L.M. and Hurwitz, S. (1963) Appendicitis with Typical Symptoms but Ectopic Appendix Due to Malrotation of Colon. California Medicine, 98, 158-159.

[30] Price, E.A. and Kane, G. (1955) Non-Rotation of Gut; with Report of Case of Left-Sided Appendiceal Abscess. South African Medical Journal, 29, 655-658.

[31] Thomas, D.W. (1952) Left-Sided Appendicitis. British Medical Journal, 2, 43. https://doi.org/10.1136/bmj.2.4774.43-a

[32] Hershman, M. (1952) Left-Sided Appendicitis. British Medical Journal, 1, 1357. https://doi.org/10.1136/bmj.1.4772.1357-a

[33] Roche, D.A. (1952) Left-Sided Appendicitis. British Medical Journal, 2, 43. https://doi.org/10.1136/bmj.2.4774.43-d

[34] Rowling, J.T. (1952) Left-Sided Appendicitis. British Medical Journal, 2, 43. https://doi.org/10.1136/bmj.2.4774.43-f

[35] Strother-Stewart, C.R. and McVey, F. (1952) Points from Letters: Left-Sided Appendicitis. British Medical Journal, 2, 165. https://doi.org/10.1136/bmj.2.4776.165

[36] Cannon, D.J. (1952) Points from Letters: Left-Sided Appendicitis. British Medical Journal, 2, 165. https://doi.org/10.1136/bmj.2.4776.165-b

[37] Haddon, J.W.L. (1945) A Case of Left-Sided Appendicitis. British Medical Journal, 2, 569. https://doi.org/10.1136/bmj.2.4425.569

[38] Grook, J.L. (1918) Left-Sided Appendicitis. Southern Medical Journal, 11, 311, 318. https://doi.org/10.1097/00007611-191804000-00012

[39] Craig, H.L. and Millar, D.M. (1962) Acute Appendicitis in Situs Inversus. British Medical Journal, 1, 563. https://doi.org/10.1136/bmj.1.5277.563

[40] Marks, C. and Pokroy, M. (1955) Situs Inversus Totalis; A Report of a Case Presenting with an Acute Abdomen. South African Medical Journal, 29, 526-527.

[41] Djohan, R.S., Rodriguez, H.E., Wiesman, I.M., Unti, J.A. and Podbielski, F.J. (2000) Laparoscopic Cholecystectomy and Appendectomy in Situs Inversus Totalis. Journal of the Society of Laparoscopic \& Robotic Surgeons, 4, 251-254.

[42] Uludag, M., Citgez, B. and Ozkurt, H. (2009) Delayed Small Bowel Perforation Due to Blunt Abdominal Trauma and Periappendicitis in a Patient with Situs Inversus Totalis: A Report of a Case. Acta Chirurgica Belgica, 109, 234-237. https://doi.org/10.1080/00015458.2009.11680412

[43] Ucar, A.E., Ergul, E., Aydin, R., Ozgun, Y.M. and Korukluoglu, B. (2007) Left-Sided Acute Appendicitis with Situs Inversus Totalis. The Internet Journal of Surgery, 12, 5.

[44] Kamiyama, T., Fujiyoshi, F., Hamada, H., Nakajo, M., Harada, O. and Haraguchi, Y. (2005) Left-Sided Acute Appendicitis with Intestinal Malrotation. Radiation Medicine, 23, 125-127.

[45] Hollander, S.C. and Springer, S.A. (2003) The Diagnosis of Acute Left-Sided Appendicitis with Computed Tomography. Pediatric Radiology, 33, 70-71. https://doi.org/10.1007/s00247-002-0829-x

[46] Du Toit, D.F. and Greeff, M. (1986) Acute Abdomen in a Patient with Situs Inversus. A Case Report. The South African Medical Journal, 69, 201-202.

[47] Winter, B. and Dyk, M. (1953) Left-Sided Acute Appendicitis. Canadian Medical 
Association Journal, 68, 278-279.

[48] Block, F.B. and Michael, M.A. (1938) Acute Appendicitis in Complete Transposition of Viscera: Report of Case with Symptoms Referable to Right Side Mechanism of Pain in Visceral Disease. Annals of Surgery, 107, 511-516. https://doi.org/10.1097/00000658-193804000-00005

[49] Willis, B.C. (1925) Appendicitis and Transposition of the Viscera. Annals of Surgery, 82, 256-259. https://doi.org/10.1097/00000658-192508000-00011

[50] Blegen, H.M. (1949) Surgery in Situs Inversus. Annals of Surgery, 129, 244-259. https://doi.org/10.1097/00000658-194902000-00009

[51] Nelson, M.J. and Pesola, G.R. (2001) Left Lower Quadrant Pain of Unusual Cause. Journal of Emergency Medicine, 20, 241-245. https://doi.org/10.1016/S0736-4679(00)00316-4

[52] Ratani, R.S., Haller, J.O., Wang, W.Y. and Yang, D.C. (2002) Role of CT in Left-Sided Acute Appendicitis: Case Report. Abdominal Imaging, 27, 18-19. https://doi.org/10.1007/s00261-001-0039-2

[53] Bider, K., Kaim, A., Wiesner, W. and Bongartz, G. (2001) Acute Appendicitis in a Young Adult with Midgut Malrotation: A Case Report. European Radiology, 11, 1171-1174. https://doi.org/10.1007/s003300000734

[54] Garg, P., Singh, M. and Marya, S.K. (1991) Intestinal Malrotation in Adults. Indian Journal of Gastroenterology, 10, 103-104.

[55] Rodriguez, O., Avilés, A., Aquino, E., Pérez Arzola, M., Cortés, F. and Monasterio, J. (2006) Acute Abdominal Symptoms as the First Presentation of a Patient with Mirror-IMAGE dextrocardia with Situs Inverus. Boletin de la Asociacion Medica de Puerto Rico, 98, 244-248.

[56] Bielecki, K., Gregorczyk, M. and Baczuk, L. (2006) Visceral Situs Inversus in Three Patients. Wiadomości Lekarskie, 59, 707-709.

[57] Tiwari, A., MacMull, S., Fox, S. and Jacob, S.A. (2006) Left Sided Abdominal Pain in a Patient with Situs Inversus. Clinical Anatomy, 19, 154-155.

https://doi.org/10.1002/ca.20201

[58] Contini, S., Dalla Valle, R. and Zinicola, R. (1998) Suspected Appendicitis in Situs Inversus Totalis: An Indication for a Laparoscopic Approach. Surg. Laparosc. Endosc., 8, 393-394.

[59] Prasad, V. (1992) Left Sided Appendicitis and Situs Inversus. Indian Journal of Gastroenterology, 11, 44-45.

[60] Pillay, S.P. (1976) Perforated Appendix in Situs Inversus Viscerum. A Case Report. South African Medical Journal, 50, 141-143.

[61] Holgersen, L.O., Kuehner, C.R. and Stanley-Brown, E.G. (1970) Acute Appendicitis in a Child with Complete Situs Inversus. Journal of Pediatric Surgery, 5, 379-380. https://doi.org/10.1016/0022-3468(70)90198-3

[62] Abel W.G. (1949) Acute Appendicitis with Concomitant Situs Inversus-Report of a Case. The New England Journal of Medicine, 241, 97-98. https://doi.org/10.1056/NEJM194907212410304

[63] Çelik, F., Güleç, S. and Gökçora, İ.H. (1986) A Case of Acute Appendicitis with Situs Inversus Totalis Simulating Ureteral Colic. Turkish Journal of Medical Sciences, 4, 147-148.

[64] Chang, K.S. (2009) 1235: Acute Appendicitis in Situs Inversus. Ultrasound in Medicine \& Biology, 35, S163. https://doi.org/10.1016/j.ultrasmedbio.2009.06.619

[65] Palanivelu, C., Rangarajan, M., John, S.J., Senthilkumar, R. and Madhankumar, 
M.V. (2007) Laparoscopic Appendectomy for Appendicitis in Uncommon Situations: The Advantages of a Tailored Approach. Singapore Medical Journal, 48, 737-740.

[66] Akbulut, S., Ulku, A., Senol, A., Tas, M. and Yagmur, Y. (2010) Left-Sided Appendicitis: Review of 95 Published Cases and a Case Report. World Journal of Gastroenterology, 16, 5598-5602. http://dx.doi.org/10.3748/wjg.v16.i44.5598

\section{Abbreviation}

LSAA: Left Sided Acute Appendicitis

SIT: Situs Inversus Totalis

MM: Midgut Malrotation

CT: Computed Tomography

HSG: Ultrasonography

UAE: United Arab Emirates 